\title{
Study on Micro-Characteristics of Microbe-Induced Calcium Carbonate Solidified Loess
}

\author{
Xiaojun Liu ${ }^{1,2, *}$, Chaofan Pan ${ }^{2} \mathbb{D}$, Jing $\mathrm{Yu}^{2, *}$ and Jinyue Fan ${ }^{2}$ \\ 1 Shaanxi Key Laboratory of Geotechnical and Underground Space Engineering, \\ College of Civil Engineering, Xi'an University of Architecture and Technology, Xi'an 710055, China \\ 2 College of Civil Engineering, $X_{i}{ }^{\prime}$ an University of Architecture and Technology, $X_{i}$ 'an 710055, China; \\ panchaofan@xauat.edu.cn (C.P.); fanjinyue@xauat.edu.cn (J.F.) \\ * Correspondence: 1xj8345@xauat.com (X.L.); yujing1506@163.com (J.Y.)
}

Citation: Liu, X.; Pan, C.; Yu, J.; Fan, J. Study on Micro-Characteristics of Microbe-Induced Calcium Carbonate Solidified Loess. Crystals 2021, 11, 1492. https://doi.org/10.3390/ cryst11121492

Academic Editors: José L. Arias and Jaime Gómez Morales

Received: 9 November 2021

Accepted: 26 November 2021

Published: 1 December 2021

Publisher's Note: MDPI stays neutra with regard to jurisdictional claims in published maps and institutional affiliations.

Copyright: (c) 2021 by the authors. Licensee MDPI, Basel, Switzerland. This article is an open access article distributed under the terms and conditions of the Creative Commons Attribution (CC BY) license (https:/ / creativecommons.org/licenses/by/ $4.0 /)$.
Abstract: Microbial-induced carbonate precipitation (MICP) has outstanding characteristics in solidifying soil, such as good fluidity, ecological environmental protection, adjustable reaction, etc., making it have a good application prospect. As a typical silty clay, the composition of loess is fine, and the microstructure is quite different from that of sand. Previous research has found that the unconfined compressive strength of loess cured by MICP can be increased by nearly four times. In this paper, by comparing the changes of structural characteristics of undisturbed loess before and after MICP solidification, the mechanism of strength improvement of loess after MICP solidification is revealed from the microscopic level. Firstly, the microstructure of loess before and after solidification is tested by scanning electron microscope, and it is found that the skeleton particles of undisturbed loess are granular, and the soil particles coexist in direct contact and indirect contact, and the pores in soil are mainly overhead pores compared with the microstructure of solidified loess, it is found that the surface contact between aggregates increases obviously, and calcium carbonate generated by MICP is adsorbed around the point contact between aggregates, which makes the contact between soil particles change from point contact to surface contact. Then, Pores (Particles) and Cracks Analysis System (PCAS) is used to quantitatively analyze the pores of loess before and after solidification. The results show that the total pore area, the maximum total pore area and porosity of soil samples decrease, and the total number of pores decreases by $13.2 \%$ compared with that before MICP solidification, indicating that a part of calcium carbonate produced by MICP reaction accumulates in tiny pores, thus reducing the number of pores. One part is cemented between soil particles, which increases the contact area of particles. Therefore, some pores of loess solidified by MICP are filled and densified, the contact area between soil particles is increased, and the strength of loess under load is obviously improved.

Keywords: MICP; micro curing mechanism; pore area; contact between soil particles

\section{Introduction}

Loess is accumulated for a long time under specific climate and natural conditions [1], and is widely distributed in China. As a special type of soil, it has remarkable characteristics, including macropore structure, vertical joint development and collapsibility. Researchers have been doing a lot of research to improve the engineering properties of loess. At present, cement, lime and chemical grouting are mostly used to improve the soil strength at home and abroad, and significant results have been achieved. However, adverse effects such as soil pollution are generated [2,3]. Microbial-induced calcium carbonate precipitation (MICP) solidified soil is favored locally and abroad as an emerging green technology. Analysis of the existing research results shows that the current research on MICP technology has two main characteristics. First, due to the high irrigability of the sand and the stable reinforcement effect, the sand is mainly used as the research object. In fact, most researchers have a strong interest in whether MICP can be widely used and its effect. Second, most of 
the studies focus on the macroscopic mechanical properties of the solidified soil, but the studies on the fine microstructure are not sufficient. In particular, there are few studies on the variation rules of the fine microstructure of the loess after MICP solidification. The fundamental reason for the change of soil engineering properties lies in the change of its microstructure, so the research is conducted from the perspective of the combination of micro and macro [4-6].

For the microscopic pore characteristics of soil, the test methods mainly include: slice method, mercury intrusion method, electron microscope scanning method, CT scanning method, gas adsorption method, etc. The mercury intrusion method $[7,8]$ has a simple principle and a fast test speed, but it causes damage to the original pore structure during the actual application of pressure, affecting the measurement results. CT scanning technology $[9,10]$ is nondestructive testing, which can obtain the three-dimensional pore distribution characteristics of soil samples, which is more intuitive, but its cost is higher and the image processing is cumbersome. With the development of high magnification, multi-function scanning electron microscopy and the continuous advancement of computer technology, more and more information can be provided by SEM pictures, and their applications are becoming more and more extensive. In recent years, a large number of scholars in China and foreign countries have studied the microstructure of loess, and have made some progress. On the basis of the two-dimensional microcosm, Wei [11] used continuous slicing technology to reconstruct the three-dimensional microstructure of the loess, qualitatively observed the contact method of the loess particle points, edges and surfaces, and quantitatively analyzed the microstructure of the particles and pores feature. Unlike two-dimensional, three-dimensional microstructure analysis can better reflect the real spatial state of loess particles, which is more conducive to the study of the collapsible mechanism of loess, and promotes the research progress of loess microstructure. Ahmad I [12] carried out microscopic morphological studies on the Kashmir loess with the aid of electron microscope scanning technology and analyzed the paleoclimate conditions corresponding to different strata of the Kashmir loess combined with macroscopic observations. Li L C [13] observed the microstructure of loess at different depths in the Yan'an area and found that the pore characteristics of loess transitioned from large and medium pores to smaller pores with stable structures and the connectivity of the pores also changed. The collapsibility of loess is unique to other soils. Chen Yang [14] used a microscope to study the microstructure of the loess in Yan'an New Area and obtained the relationship between the microstructure change after the loess collapse and the loess collapsibility. Shao X [15] found that the collapsibility of remolded loess mainly depends on the intergranular pore size of the remolded loess and the reduction of intergranular pore size after loading and wetting. Jiang M [16] studied the microstructural evolution of natural loess and remodeled loess under different stress paths to prove the influence of microstructural features, especially cemented bonds and stress paths, on mechanical behavior. Li P [17] found that as the stress level increases, the pores between larger aggregates change into smaller secondary aggregate pores, and the pore direction is still random. Zhang W [18] made statistics on the physical indicators, mineralogical characteristics and collapse potential of the coastal loess, and the results showed that the porosity of the soil body after the collapse is small, and the medium porosity is the main cause of the collapse. Many researchers used IPP, MATLAB, and other software to quantitatively analyze the microstructure of loess based on qualitative analysis [19,20]. Fang X W [21] used Scion Image software to quantitatively analyze the characteristics of the pore area, distribution fractal dimension and other parameters of the loess at different depths.

To sum up, there is still a lack of research on micro-characteristics of loess solidified by MICP, and it is difficult to deeply understand and analyze the cementation mechanism of MICP at the microscopic level. In this paper, on the basis of existing research, $\mathrm{Xi}^{\prime}$ an loess is taken as the research object. According to the suitable proportion of MICP solidified loess obtained by previous experiments, the loess is treated by MICP solidification, and the soil samples before and after solidification are scanned by field emission scanning 
electron microscope to obtain the microstructure characteristics of loess in different states. By comparing and analyzing the microstructure of undisturbed loess and MICP-solidified loess, the change of microstructure of undisturbed loess and MICP-solidified loess is obtained, and the cementation mechanism and strength improvement of MICP-solidified loess is revealed, which provides a basis for the application of MICP in loess reinforcement.

\section{Materials and Methods}

\subsection{Test Soil and Test Solution}

The loess in a foundation pit in Xi'an is selected as the research object, and the disturbance to the original soil is avoided as much as possible during the borrowing process. The basic physical indexes of soil after natural air drying are shown in Table 1:

Table 1. Physical indicators of undisturbed loess.

\begin{tabular}{ccccc}
\hline Dry Density $\mathbf{g} / \mathrm{cm}^{\mathbf{3}}$ & Porosity $\%$ & Liquid Limit \% & Plastic Limit \% & Plastic Index \% \\
\hline 1.49 & 45.62 & 36.5 & 19 & 17.5 \\
\hline
\end{tabular}

Figure $1 \mathrm{a}$ is the loess surface morphology after natural air drying. Xi'an loess is brownish yellow with dense structure and rich pores visible to the naked eye. Figure $1 \mathrm{~b}$ describes the grain gradation of undisturbed loess. According to the figure, it can be seen that the grain gradation of this loess is good.

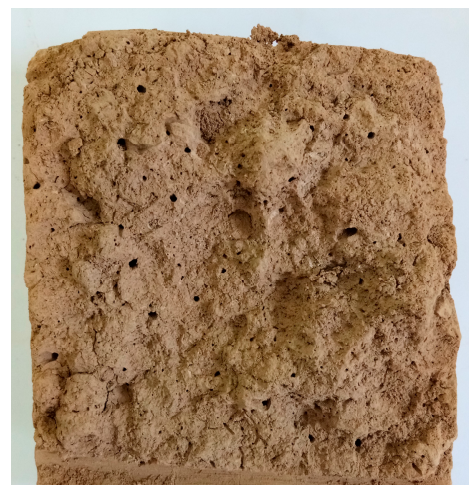

(a)

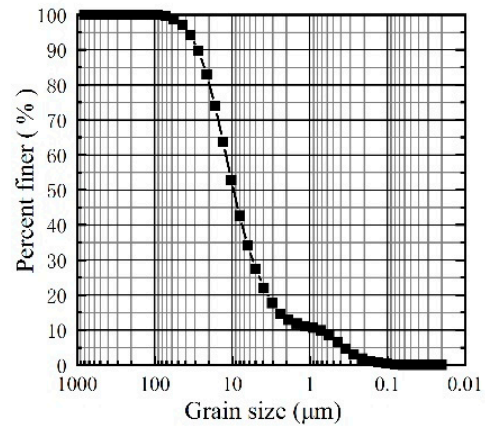

(b)

Figure 1. Sample section and particle gradation curve. (a) Sectional view of loess sample; (b) Loess particle gradation curve.

The strain used in this experiment is Bacillus pasteureus, which is purchased from China Microbial Culture Collection Center. Every liter of culture medium contains $20 \mathrm{~g}$ yeast extract, $10 \mathrm{~g} \mathrm{NH}_{4} \mathrm{Cl}, 10 \mathrm{mg} \mathrm{MnSO}_{4} \cdot \mathrm{H}_{2} \mathrm{O}$ and $24 \mathrm{mg} \mathrm{NiCl} \cdot 6 \mathrm{H}_{2} \mathrm{O}$, and the $\mathrm{pH}$ is adjusted to 9.0 with $1 \mathrm{~mol} / \mathrm{L} \mathrm{NaOH}$. After being sterilized by high pressure steam for $20 \mathrm{~min}$, the prepared culture solution is placed in an ultra-clean workbench and cooled to room temperature, and then inoculated with bacteria. The inoculated culture solution is cultured in a constant temperature oscillating incubator at $30^{\circ} \mathrm{C}$ and $120 \mathrm{rpm}$ for $24 \mathrm{~h}$, and its absorbance and urease activity are measured. In this experiment, the bacterial liquid concentration $\mathrm{OD}_{600}$ is 1.5 , and the cementing liquid is a mixture of $\mathrm{CaCl}_{2}$ and urea with a concentration of $1 \mathrm{~mol} / \mathrm{L}$ [22], in which $\mathrm{CaCl}_{2}$ provides calcium source for MICP process, and urea provides nitrogen source and $\mathrm{CO}_{3}{ }^{2-}$ for reaction under the hydrolysis of urease.

\subsection{Strength Test and Scanning Electron Microscope Test of Loess Solidification}

In the test, the soil samples are reinforced by vacuumizing and grouting step by step. Filter paper and permeable stone are placed on the upper and lower surfaces of soil samples to reduce the erosion of soil samples by solution. The remolded soil sample is covered with a rubber film, which reduces the seepage along the soil wall due to the side wall effect. In order to better penetrate the solution into loess, a vacuum pumping device is 
connected to the lower end of the mold. At first, $15 \mathrm{~mL}$ of bacteria solution is injected into the loess soil sample at the speed of $5 \mathrm{~mL} / \mathrm{min}$, and after standing for two hours, $15 \mathrm{~mL}$ of cementing solution is injected into the loess soil sample at the speed of $5 \mathrm{~mL} / \mathrm{min}$, and stands for six hours, which is a cycle, and each soil sample is treated for six cycles. After the curing test, take out the soil sample. The cured soil sample is shown in Figure 2 below. The loess soil sample after microbial curing is loaded by strain controlled triaxial apparatus at a loading rate of $0.368 \mathrm{~mm} / \mathrm{min}$ until the sample fails. The peak stress is taken as the nonlateral compressive strength of the soil sample.

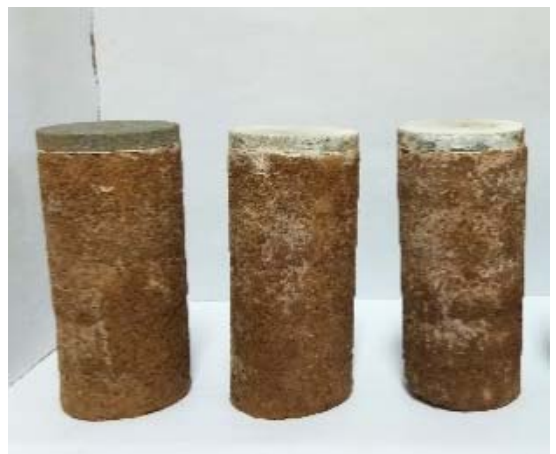

(a)

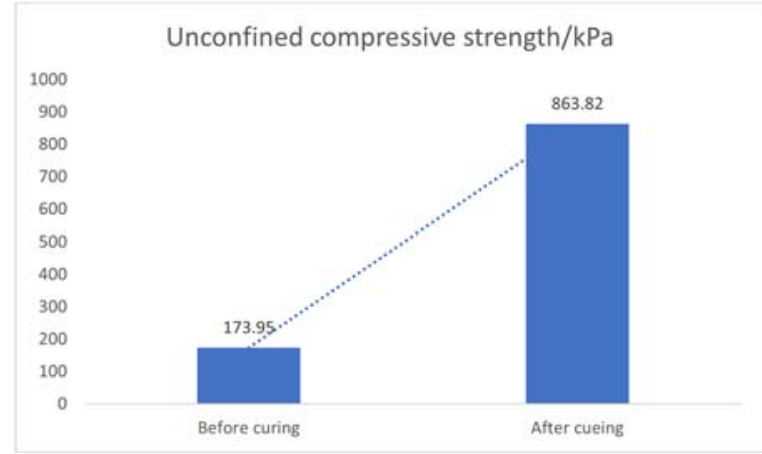

(b)

Figure 2. Change diagram of unconfined compressive strength of loess sample after MICP curing and after curing. (a) Loess sample cured by MICP; (b) Change diagram of unconfined compressive strength before and after MICP curing.

The undisturbed loess and MICP-cured loess are scanned by electron microscope. Five groups of loess samples are made in each case, and each sample scans at five points. The surface morphology and fracture of metal materials, polymer materials and semiconductor materials are analyzed by using secondary electron or backscattered electron signals, and the elements are qualitatively and semi-quantitatively analyzed with an energy dispersive spectrometer. During scanning, we try to avoid singular points, move within the visual field, and select representative areas for shooting. Sample preparation method: cut undisturbed loess soil sample into small pieces of $2 \mathrm{~cm} \times 1 \mathrm{~cm} \times 1 \mathrm{~cm}$, carve a $1 \mathrm{~mm}$ deep groove in the middle, dry and break to obtain fresh section. The specific steps of MICP curing are as follows: firstly, drop 5 drops of bacterial liquid on the fresh section, then drop 5 drops of cementing liquid after $10 \mathrm{~min}$ as a cycle, and treat it six times in total, once in the morning and once in the evening. Microbial treatment is carried out in an ultra-clean workbench to prevent dust and impurities from falling on the surface of soil samples. Before scanning by electron microscope, the dried soil samples are placed in a vacuum coating machine for gold spraying treatment.

\section{Results}

\subsection{Strength Change of MICP Solidified Loess}

Firstly, the unconfined compressive strength of the soil sample without MICP treatment is tested, and the unconfined compressive strength of the soil sample without MICP treatment is $173.95 \mathrm{kPa}$. The unconfined strength of soil samples cured by MICP is also tested, and unconfined strength is obtained. In this experiment, the concentration of bacteria solution $\mathrm{OD}_{600}$ is 1.5 , and the concentration of cementing solution is $1 \mathrm{~mol} / \mathrm{L}$. According to the previous test results of the research group, this concentration combination is the best concentration combination for the reaction. At this time, the unconfined compressive strength of the soil sample is $863.8 \mathrm{kPa}$, which is about 4 times higher than that of the soil sample without MICP treatment, which verifies the feasibility of MICP technology in solidifying loess and lays a foundation for the following microscopic characteristics research. Figure 2a shows the shape of the standard sample after several rounds of MICP reaction, and the white calcium carbonate precipitate generated by MICP reaction can be clearly 
seen on the sample and Figure $2 \mathrm{~b}$ shows the improvement of unconfined compressive strength of loess treated by MICP through column diagram.

\subsection{MICP Solidified Loess Microscopic Characteristics Changes}

\subsubsection{Changes of Particle Contact State before and after MICP}

Through the analysis of undisturbed loess and observation of SEMmicrophotographs. When scanning with an electron microscope, the magnifications of the soil samples are all 200, 500, 1000, 2000 and 4000. It can be seen that the skeleton particles of Xi'an loess are "agglomerates". Among them, the skeleton particles are composed of clots, many crumbs and small particles; The skeleton particles connect with each other, bite each other and transfer stress, which plays an important role in the stability of loess.

Through analysis, the contact modes between soil particles can be divided into direct point contact, indirect point contact, direct surface contact and indirect surface contact. (1) Direct point contact refers to the direct contact between loess skeleton particles, with small contact area and no salt crystals and clay particles at the contact points. Under the same stress level, compared with other contact methods, the stress concentration is more obvious, so the connection of contact points is easily damaged under the action of immersion and compression; (2) Clay particles or salt crystals exist between the particles in indirect point contact, but the contact area is still small. When immersed in water, clay minerals at the joint soften or carbonate crystals dissolve, which easily causes collapsible deformation; (3) Direct surface contact means that the skeleton particles are in direct contact with a large contact area, so only when the external force is large enough can the contact relationship of the particles be destroyed and the dislocation occur, so the contact mode of skeleton particles in loess is relatively stable; (4) There are clay particles and cementing materials among the skeleton particles in indirect surface contact, and the contact area is large. This connection mode between skeleton particles is relatively stable, and the ability to resist external damage is strong.

Figure 3a is an SEM microphotograph of undisturbed loess. It can be seen that there are many aggregates with different sizes and shapes in loess. The aggregate size is mainly between $10 \mu \mathrm{m}$ and $30 \mu \mathrm{m}$. It can be seen from the SEM image enlarged by 2000 times in Figure $3 \mathrm{~b}$ that silt particles are adsorbed by more clay particles, forming cohesive agglomerates, and the conglomerates contact with each other in different ways. Surface contact can increase the cementation degree of soil skeleton particles, which is beneficial to the stability of loess structure. Point contact is also a connection mode that cannot be ignored in loess particles. Most of them are angular and angular contact between soil particles, which are sensitive to water. When the soil is affected by external force and moisture, the loess skeleton particles interact with each other and break, which makes the contact and connection between particles unstable, resulting in macroscopic deformation of loess. Therefore, the collapsibility of loess is greatly affected by point contact, and there are more point contact and direct contact in undisturbed loess.

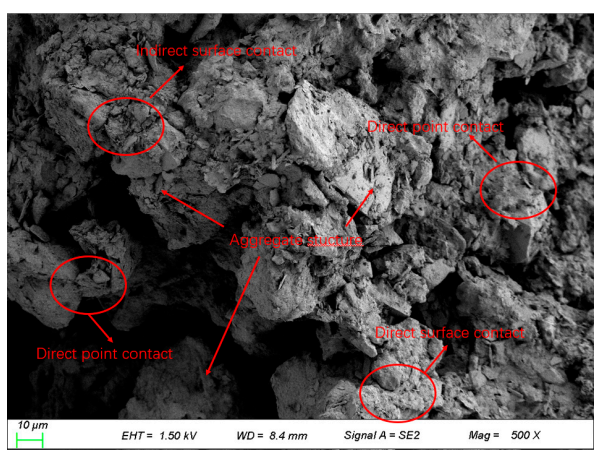

(a)

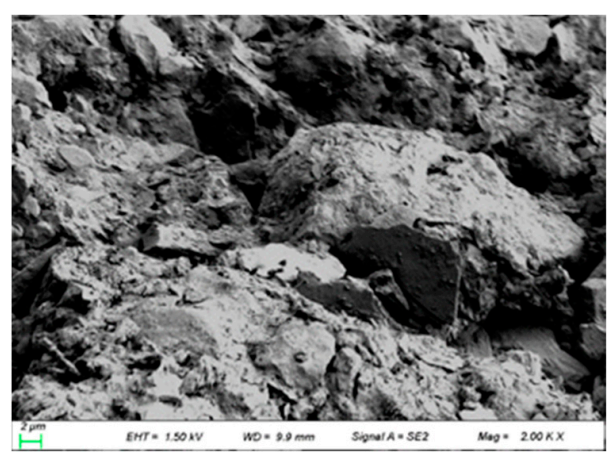

(b)

Figure 3. Particle contact state before MICP curing. (a) 500 times of undisturbed loess; (b) 2000 times of undisturbed loess. 
Figure 4 is the SEM scanning image of loess solidified by MICP. It can be seen that the characteristics of loess solidified by MICP are as follows: the surface contact between aggregates (direct surface contact and indirect surface contact) increases obviously. This is because the calcium carbonate induced by microorganisms can act as a cementing material between aggregates, and the generated calcium carbonate is adsorbed around the point contact between aggregates, which makes the point contact evolve into surface contact. The overhead pore area of loess becomes smaller, and many cemented films are adsorbed and coated on the surface of each granule, and the particle shape tends to be smooth compared with the undisturbed loess. The micropores in grains are relatively reduced, because calcium carbonate precipitates induced by microorganisms can fill and cement the micropores in grains.

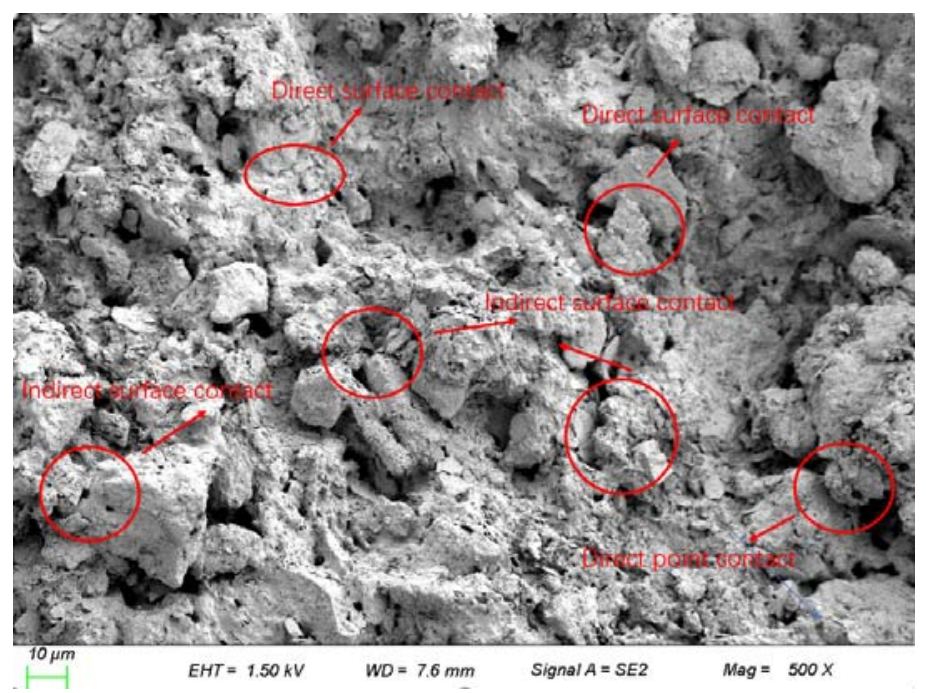

Figure 4. Particle contact state after MICP curing.

\subsubsection{The Change of Pore Characteristics of MICP Solidified Loess}

Through observation and analysis, it is found that there are all kinds of pores in loess, mainly overhead pores, accompanied by many micro, small pores and medium pores. Loess pores can reflect the characteristics of the soil, and the pores in the soil can be divided into: (1) Scaffolding pores (overhead pores), which are formed by the mutual support and accumulation of many skeleton particles. The pore diameter is sometimes larger than the diameter of the particles that make up the pores. These pores are diverse and irregular in shape, and are prone to collapse or compression deformation under the action of water immersion or certain pressure; (2) Mosaic pores (intergranular pores), which are gaps formed by interpenetration and close accumulation of skeleton particles. Mosaic pores are mostly slit-shaped, generally smaller than the diameter of surrounding particles, relatively stable, and not prone to collapse. If the external force is large enough or the water is soaked, some embedded pores will become smaller or filled with finer particles. After observation and analysis, the mosaic pores in $\mathrm{Xi}^{\prime}$ an loess have a stable structure due to the interlocking among grains; (3) Cementitious pores: Cementitious pores in $\mathrm{Xi}^{\prime}$ an loess mostly exist in clay cements, with a large number and small volume, most of which are small pores with poor connectivity, diverse shapes and stable structure. Table 2 shows the typical pore morphology of loess in Xi'an.

Figure $5 a$ is the SEM image magnified by 200 times and Figure $5 b$ is the SEM image magnified by 500 times. The pore structure of the undisturbed loess can be clearly seen. The long axis size of the pores that can be observed in the figure is between $5 \mu \mathrm{m}$ and $80 \mu \mathrm{m}$. The largest long axis diameter of the overhead pores on the visible plane in the SEM image can reach $80 \mu \mathrm{m}$. When magnified 500 times, there are many intragranular pores formed by the aggregation and contact of clay particles on the aggregates. Compared with the overhead pores, this pore has less impact on the structure of loess. Mosaic pores 
are produced by the contact between particles and are in the shape of cracks. The width of the cracks in the image plane is about $4 \mu \mathrm{m}$, and the formed pores are relatively small. When subjected to external force, the particles are only compressed by force, but no major deformation occurs, so its structural effect on loess is small and relatively stable.

Table 2. Classification of pore genesis.

\begin{tabular}{|c|c|c|c|}
\hline Classification & Stent Pores & Mosaic Pores & Cement Pores \\
\hline Loess pore map & & & \\
\hline
\end{tabular}

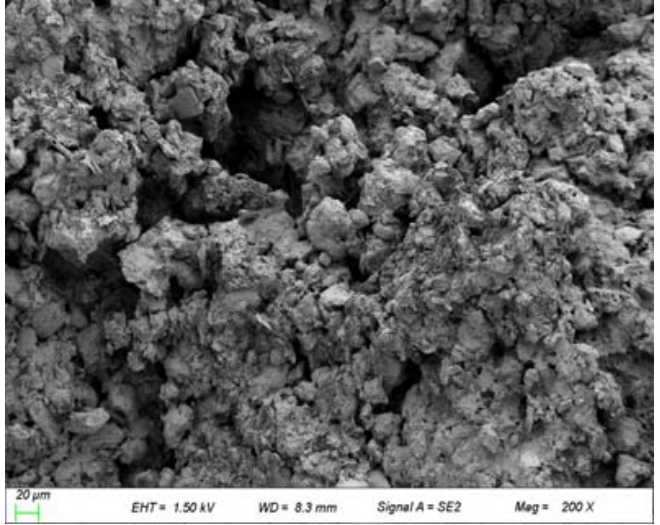

(a)

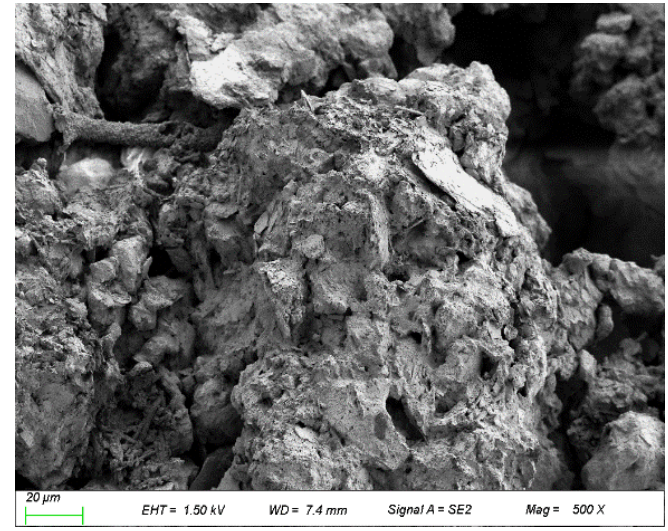

(b)

Figure 5. Pore microstructure of loess before MICP curing. (a) Loess structure before solidification under 200 times; (b) Loess structure before solidification under 500 times.

The following Figure 6a is the SEM image of loess after MICP solidification by 4000 times. Figure $6 \mathrm{~b}$ shows two ways of MICP curing loess, one is cementation, the other is filling. Figure $6 c$ is the SEM image of loess after MICP solidification by 2000 times it can be observed that a large number of rod-like substances are adsorbed on the surface of soil particles, which is similar in size and shape to the microorganism observed under a microscope, with a length of about $2-5 \mu \mathrm{m}$ and a diameter of about $0.5 \mu \mathrm{m}$, and it is judged that it is Bacillus pasteureus. Compared with uncured loess, calcium carbonate crystals are formed on the surface of loess particles after MICP curing, and some of these calcium carbonate precipitates are deposited in the pores between soil particles and play a filling role. Some adsorption is connected between two soil particles, which plays a cementation role. Some of them cover the surface of soil particles, which increases the roughness of the surface of soil particles. Meanwhile, it is observed that bacteria tend to accumulate and grow in places with smaller pores.

The microscopic structure of soil samples is quantitatively analyzed by the image processing software Pores (particles) and Cracks Analysis System (PCAS) developed by Nanjing University. PCAS can automatically and accurately identify various pores and cracks in the image, and obtain the geometric parameters and statistical parameters of loess microstructure, so as to quantitatively evaluate the microscopic structure characteristics of loess. Figure 7 is a picture of undisturbed loess after binarization. 


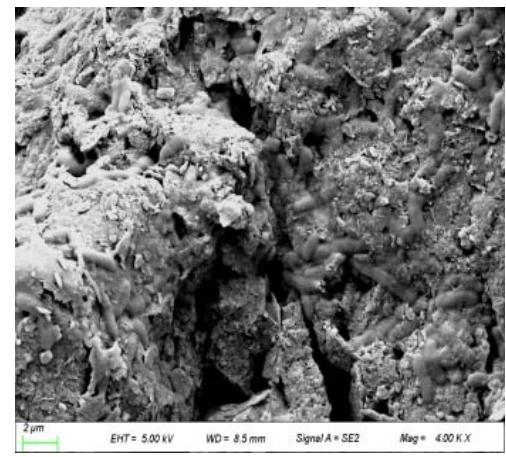

(a)

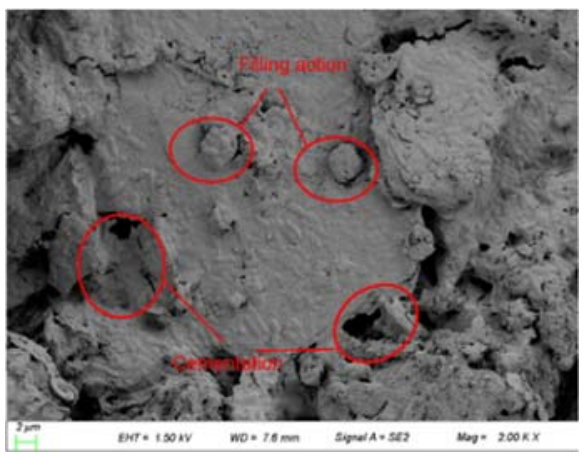

(b)

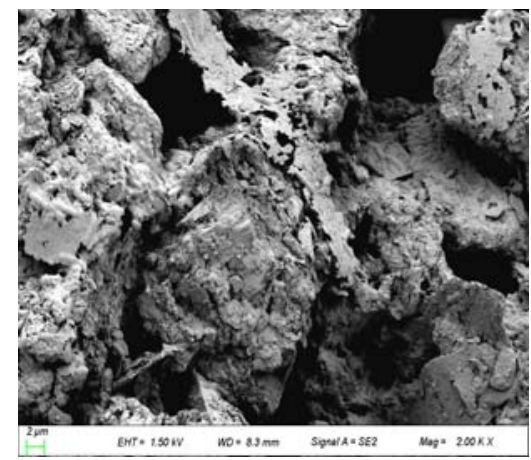

(c)

Figure 6. Pore microstructure of loess cured by MICP. (a) Loess solidify at 4000 times; (b) MICP curing loess mode; (c) Loess solidify at 2000 times.
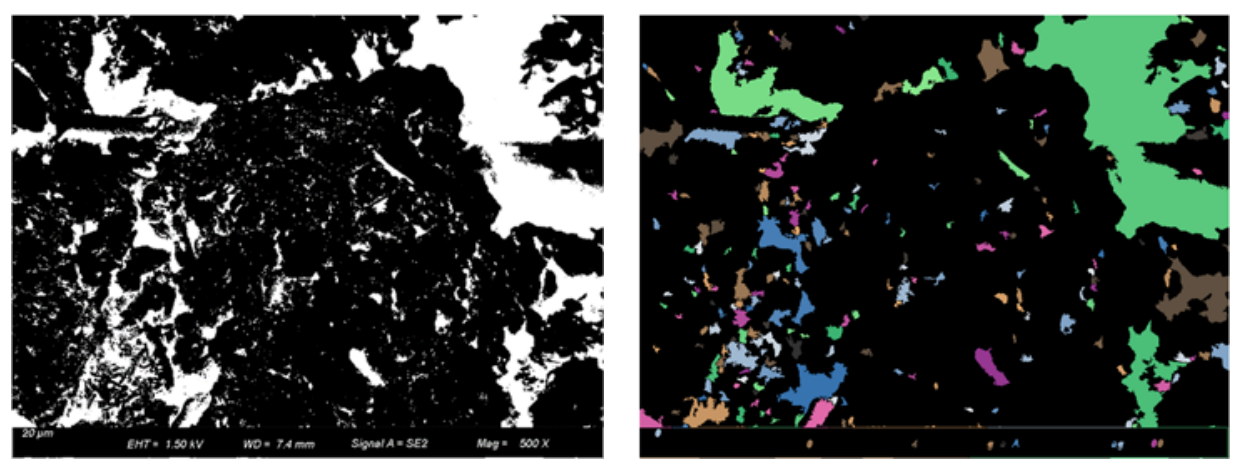

Figure 7. Picture of undisturbed loess after binarization.

Usually, the length of Bacillus pasteureus is about $2-5 \mu \mathrm{m}$, and the diameter of calcium carbonate produced by the reaction is about $20 \mu \mathrm{m}$. Therefore, the pores in loess can be classified as follows: pores larger than $20 \mu \mathrm{m}$ are large pores, 5-20 $\mu \mathrm{m}$ are medium pores, 2-5 $\mu \mathrm{m}$ are small pores, and smaller than $2 \mu \mathrm{m}$ are micropores. Average pore diameter can be obtained by using a formula, where $S$ is pore area, and classification results are shown in Tables 3 and 4 below.

Table 3. Areas of different types of pores $\left(\mu \mathrm{m}^{2}\right)$.

\begin{tabular}{ccccc}
\hline Soil Sample & $\begin{array}{c}\text { Microporosity } \\
<\mathbf{2} \boldsymbol{\mu \mathbf { m }}\end{array}$ & $\begin{array}{c}\text { Small Pores } \\
\mathbf{2 - 5} \boldsymbol{\mu \mathbf { m }}\end{array}$ & $\begin{array}{c}\text { Mesopores 5-20 } \\
\boldsymbol{\mu m}\end{array}$ & $\begin{array}{c}\text { Macropores } \\
\mathbf{2 0} \boldsymbol{\mu m}\end{array}$ \\
\hline Undisturbed loess & 213.14 & 1715.38 & 2806.96 & 1909.39 \\
Solidified loess & 166.34 & 1586.86 & 2586.16 & 1403.62 \\
\hline
\end{tabular}

Table 4. Number of different types of pores.

\begin{tabular}{cccccc}
\hline Soil Sample & $\begin{array}{c}\text { Micropores } \\
<\mathbf{2} \boldsymbol{\mu \mathbf { m }}\end{array}$ & $\begin{array}{c}\text { Small Pores } \\
\mathbf{2 - 5} \boldsymbol{\mu \mathbf { m }}\end{array}$ & $\begin{array}{c}\text { Mesopores } \\
\mathbf{5 - 2 0} \boldsymbol{\mu \mathbf { m }}\end{array}$ & $\begin{array}{c}\text { Macropores } \\
\mathbf{2 0} \boldsymbol{\mu m}\end{array}$ & $\begin{array}{c}\text { Total Number } \\
\text { of Pores }\end{array}$ \\
\hline Undisturbed loess & 76.3 & 265.1 & 46 & 2.5 & 389.9 \\
Solidified loess & 59.5 & 229.9 & 46.5 & 2.2 & 338.1 \\
\hline
\end{tabular}

Comprehensive analysis of Tables 3 and 4 shows that all kinds of pore areas in loess cured by MICP are reduced, which indicates that part of calcium carbonate generated by MICP reaction is filled between tiny pores, reducing pore area, and part of calcium carbonate is adsorbed and cemented on the surface of soil particles, which can reduce the size of macropores to a certain extent, and the reduction of unstable macropores, i.e., overhead pore area, is beneficial to the stability of soil. After MICP curing, the total number of pores in soil samples decreases by $13.2 \%$, and the number of micro- and small 
pores decreases obviously, which indicates that calcium carbonate produced by MICP reaction mainly gathers in micropores, reducing the number of pores, while the other part is cemented between soil particles, increasing the particle area and reducing the pore area.

Based on digital image recognition technology, it can be known that the particles and pores in the image are assembled by pixels. The definition of the image area can be expressed as the number of pixels in a unit area, and the definition of the image perimeter can be expressed as a collection of pixel boundary lengths in a unit segment. The parameters obtained through PCAS are all in pixels. The actual pore particle area can be obtained through image resolution.

In the equations: $\mathrm{S}, \mathrm{C}$ are the actual area and actual perimeter respectively; S0, C0 are the pixel area and pixel perimeter, respectively; $\mathrm{R}$ is the resolution of the image. The resolution of this paper is $0.222 \mu \mathrm{m} /$ pixel. The real conversion of pixel geometric parameters can be carried out through the above calculation.

The porosity is the ratio of the pore area to the total area in the statistical area, and the calculation equation is as follows:

$$
\lambda=A_{\mathrm{p}} / A
$$

where: $A_{p}$ is the area occupied by pores in the statistical area; $A$ is the total area of the statistical area.

The shape factor is calculated from the area $S$ and perimeter $C$ of the block [20], which reflects the shape of pores or particles.

The area-perimeter method is used to express the fractal characteristics of particles or pores, and the fractal dimension $D_{f}$ reflects the change law of the complexity of particles (or pores) with their area [23]. The relationship between the fractal dimension and the perimeter area of the particle can be expressed as

$$
\log (C)=\left(D_{f} / 2\right) \cdot \log (S)+C_{1}
$$

where, $C$ is the perimeter, $S$ is the area, and $C_{1}$ is a constant. The area and perimeter are cast on a double logarithmic table, the data points are in a simple linear relationship, and the slope of the fitted line is obtained by the least square method, which is $D_{f} / 2$. The value of $D_{f}$ is generally between 1-2. The larger the $D$, the more complex the pore structure, the farther the spatial morphology of the pores deviate from the smooth surface, the more dispersed the distribution of soil particles, and the weaker the degree of agglomeration of soil particles [24].

Probability entropy characterizes the order of pore or particle system arrangement, and its definition is as follows:

$$
H_{m}=-\sum_{i=1}^{n} P_{i} \cdot \log _{n}\left(P_{i}\right)
$$

where, $P i$ is the percentage content of the pores or particles in the long axis direction in a specific interval, $n$ is the number of azimuth zones divided between $0-180^{\circ}$ in the unit array direction, and the software program is equally divided by $10^{\circ}$ units, $n=18$. Obviously, the value of $H_{m}$ is between $0-1$, when $H_{m}=0$, that is, all the particles or pores are arranged in the same direction, that is, the degree of order is the highest. When $H_{m}=1$, it indicates that particles or pores are completely randomly arranged. In each azimuth zone, particles or pores appear with the same probability and complete disorder.

Based on the above method, the SEM images of loess before and after solidification are processed and transformed by software, and the microscopic statistical parameters are obtained. The data obtained by taking their average values are shown in Table 5 . 
Table 5. Statistical parameters of soil pores.

\begin{tabular}{ccccccc}
\hline Soil State & $\begin{array}{c}\text { Total Pore } \\
\text { Area } A_{\boldsymbol{p}}\left(\mu \mathrm{m}^{2}\right)\end{array}$ & $\begin{array}{c}\text { Maximum Pore } \\
\text { Area } \boldsymbol{A}_{\boldsymbol{~} \mathrm{m}}\left(\boldsymbol{\mu m}^{2}\right)\end{array}$ & Porosity \% & $\begin{array}{c}\text { Average Pore Shape } \\
\text { Coefficient }\end{array}$ & $\begin{array}{c}\text { Pore Fractal } \\
\text { Dimension }\end{array}$ & $\begin{array}{c}\text { Entropy of Porosity } \\
\text { Probability }\end{array}$ \\
\hline Undisturbed loess & 8228 & 1939 & $21.19 \%$ & 0.3822 & 1.2908 & 0.9875 \\
Solidified loess & 6943 & 1186 & $17.88 \%$ & 0.3938 & 1.2495 & 0.9755 \\
\hline
\end{tabular}

It can be seen from the above table that the total pore area, the maximum total pore area and porosity of soil samples are reduced after MICP solidification, which indicates that calcium carbonate precipitates generated after microbial solidification fill the pores and serve as the connecting cement between soil particles. Partially induced calcium carbonate is adsorbed on the surface of soil particles. Although calcium carbonate adsorbed on the surface of soil particles can not completely fill macropores, it can reduce the size of macropores to a certain extent. The average shape coefficient of pores after MICP solidification is 0.3938 , which is larger than 0.3822 of undisturbed loess, and the fractal dimension of pores is 1.2495 , which is smaller than 1.2908 of undisturbed loess. The fractal dimension of pores is 1.2495, which is smaller than that of undisturbed loess (1.2908), indicating that the distribution of loess particles after solidification is denser and the degree of soil particles is higher. After solidification, the porosity probability entropy of loess also decreases by 0.012 , which is negligible, that is, the order of voids and pores before and after solidification is relatively poor.

\subsection{Microcosmic Mechanism of MICP Solidifying Loess}

Through quantitative analysis of SEM images and PCAS of loess before and after MICP curing, it can be observed and found that microbial-induced calcium carbonate mainly plays a cementation role among loess particles, but has a limited filling effect on overhead pores. Generally, the radius of overhead pores is larger, which indicates that bacteria tend to adsorb on the surface of soil particles and both sides of the contact point of particles. When the cementing solution is dripped, the calcium carbonate precipitate produced can play an effective role in cementing, which increases the cohesion of loess and has a certain solidification effect on loess. The distribution of calcium carbonate deposition depends on the distribution of different pores in loess. There is no uniformity and regularity in the distribution of overhead pores, mosaic pores and cement pores in loess. Therefore, the deposition of calcium carbonate also has the characteristics of random distribution, which is not evenly distributed on the loess section. Among them, calcium carbonate, which plays a cementation role in mosaic pores and cementation pores, because it increases the mutual occlusion and contact area between loess particles, which is conducive to the stability of loess particles. Calcium carbonate, which plays a role of "weak cementation", easily falls into larger pores in case of water or pressure, but the filling calcium carbonate also increases soil density, which is also conducive to soil stability to a certain extent. However, the filling calcium carbonate crystals will be stacked and enlarged with the increase of injection times of bacteria solution and cementing solution, which will eventually cement adjacent soil particles together. Therefore, in the process of solidifying loess, the strength of soil can be improved by increasing grouting times.

\section{Conclusions}

This paper takes $\mathrm{Xi}^{\prime}$ an loess as the research object, uses the MICP processing method to process the loess sample, obtains its microscopic image through electron microscope scanning, and systematically analyzes the morphological characteristics and connection methods of soil particles and pores based on the obtained images. The pore morphology is quantitatively analyzed by PCAS image processing software. The following main conclusions are drawn:

(1) The skeleton particles of undisturbed loess are mainly granular particles, and the granular particles aggregate with clay particles and flocculent cementation materials 
of loess. The connection modes of each granule are direct point contact, direct surface contact, indirect point contact and indirect surface contact.

(2) In the loess solidified by MICP, the cementation substances produced are mainly cementation at both sides of particle contact points, which makes the point contact between particles gradually evolve into surface contact, and the flocculent cementation substances produced on the surface of skeleton particles increase, thus increasing the cohesion of soil.

(3) Calcium carbonate, which plays a cementation role in embedded pores and cementation pores, plays a "strong cementation" role, because it increases the mutual occlusion and contact area between loess particles, which is conducive to the stability of loess particles, while calcium carbonate, which plays a filling role, plays a "weak cementation" role. According to the quantitative analysis of PACS software, the total pore area and maximum pore area of loess cured by MICP decrease. As the generated cementing material fills both sides of the point contact, the average shape coefficient of pores increases. The generated cementing material can increase the compactness of adjacent particles and reduce the fractal dimension of pores.

(4) After MICP solidification, all kinds of pore areas in loess decrease, which is beneficial to the stability of the soil. After MICP solidification, the total number of pores in soil samples decreases by $13.2 \%$, which indicates that calcium carbonate generated by MICP reaction partly aggregate in tiny pores, reduce the number of pores, and partly cement among soil particles, increasing particle area and reducing pore area.

Author Contributions: X.L. put forward ideas for the whole study and set goals for the article, and raised funds for the research; X.L. and J.Y. reviewed and revised this manuscript at the same time; J.Y. gave supervision and guidance to the development of this experiment; C.P. and J.F. completed the experimental part of this study; C.P. also wrote the first draft of this manuscript and J.F. also analyzed the results of electron microscope test by PCAS software. All authors have read and agreed to the published version of the manuscript.

Funding: The authors deeply appreciate the financial support from the Shaanxi Natural Science Basic Research Project (Grant no.2020JM-483) and the National Natural Science Foundation of China (NSFC) (Grant no.51408464). This paper is also funded by the China Scholarship Council.

Institutional Review Board Statement: Ethics approval and consent to participate.

Informed Consent Statement: Not applicable.

Data Availability Statement: The data used to support the findings of this study are available from the corresponding author upon request.

Conflicts of Interest: We declare that we have no financial and personal relationships with other people or organizations that can inappropriately influence our work, there is no professional or other personal interest of any nature or kind in any product, service and/or company that could be construed as influencing the position presented in, or the review of, the manuscript entitled.

\section{References}

1. Liu, Z.D. Loess Mechanics and Engineering; Shaanxi Science and Technology Press: Xi'an, China, 1997.

2. Chu, J.; Ivano, V.; He, J.; Naeimi, M.; Li, B.; Stabnikov, V. Development of microbial geotechnology in Singapore. In Proceedings of the Geofrontiers: Advances in Geotechnical Engineering, Dallas, TX, USA, 13-16 March 2011.

3. Karol, R.H. Chemical Grouting and Soil Stabilization; Marcel Dekker: New York, NY, USA, 2007.

4. Muñoz-Castelblanco, J.A.; Pereira, J.M.; Delage, P.; Cui, Y.J. The water retention properties of a natural unsaturated loess from northern France. Geotechnique 2012, 62, 95-106. [CrossRef]

5. Wen, B.P.; Yan, Y.J. Influence of structure on shear characteristics of the unsaturated loess in Lanzhou, China. Eng. Geol. 2014, 168, 46-58. [CrossRef]

6. Liu, Z.; Liu, F.; Ma, F.; Wang, M.; Bai, X.; Zheng, Y.; Yin, H.; Zhang, G. Collapsibility, composition, and microstructure of loess in China. Can. Geotech. J. 2015, 53, 673-686. [CrossRef]

7. Dim, P.E.; Fletcher, R.S.; Rigby, S.P. Improving the accuracy of catalyst pore size distributions from mercury porosimetry using mercury thermoporometry. Chem. Eng. Sci. 2016, 140, 291-298. [CrossRef] 
8. Bafarawa, B.; Nepryahin, A.; Ji, L.; Holt, E.M.; Wang, J.; Rigby, S.P. Combining mercury thermoporometry with integrated gas sorption and mercury porosimetry to improve accuracy of pore-size distributions for disordered solids. J. Colloid Interface Sci. 2014, 426, 72-79. [CrossRef] [PubMed]

9. Li, G.; Fu, Y.; Li, B.; Zheng, T.; Wu, F.; Peng, G.; Xiao, T. Micro-characteristics of soil aggregate breakdown under raindrop action. Catena 2018, 162, 354-359. [CrossRef]

10. Gao, L.; Wang, B.; Li, S.; Wu, H.; Wu, X.; Liang, G.; Gong, D.; Zhang, X.; Cai, D.; Degré, A. Soil wet aggregate distribution and pore size distribution under different tillage systems after 16 years in the Loess Plateau of China. Catena 2018, 173, 38-47. [CrossRef]

11. Wei, T.; Fan, W.; Yu, N.; Wei, Y.-N. Three-dimensional microstructure characterization of loess based on a serial sectioning technique. Eng. Geol. 2019, 261, 105265. [CrossRef]

12. Ahmad, I.; Chandra, R. Micromorphological Study of Kashmir Loess-Paleosol Sediments: A Tool for Stratigraphic and Paleoclimatic Reconstruction. Earth Sci. India 2019, 12, 83-104.

13. Li, L.C. Experimental Study on the Microstructure of Yan'an Malan Loess; Chang'an University: Xi'an, China, 2017.

14. Chen, Y.; Li, X.A.; Huang, R.Q.; Huang, L.; Li, L.; Hong, B.; Liu, Z.; Cai, W. Micro-experimental study on factors affecting the collapsibility of loess. J. Eng. Geol. 2015, 23, 646-653.

15. Shao, X.; Zhang, H.; Tan, Y. Collapse behavior and microstructural alteration of remolded loess under graded wetting tests. Eng. Geol. 2018, 233, 11-22. [CrossRef]

16. Jiang, M.; Zhang, F.; Hu, H.; Cui, Y.; Peng, J. Structural characterization of natural loess and remolded loess under triaxial tests. Eng. Geol. 2014, 181, 249-260. [CrossRef]

17. Li, P.; Xie, W.; Pak, R.Y.; Vanapalli, S.K. Microstructural evolution of loess soils from the Loess Plateau of China. Catena 2018, 173, 276-288. [CrossRef]

18. Zhang, W.; Sun, Y.; Chen, W.; Song, Y.; Zhang, J. Collapsibility, composition, and microfabric of the coastal zone loess around the Bohai Sea, China. Eng. Geol. 2019, 257, 105142. [CrossRef]

19. Xue, T. The Influence of Freeze-Thaw Cycles on the Structural Properties of Loess; Xi'an University of Technology: Xi'an, China, 2017.

20. Liu, C.; Shi, B.; Zhou, J.; Tang, C. Quantification and characterization of microporosity by image processing, geometric measurement and statistical methods: Application on SEM images of clay materials. Appl. Clay Sci. 2011, 54, 97-106. [CrossRef]

21. Fang, X.W.; Shen, C.N.; Li, C.H. Microstructure characteristics and quantitative analysis of loess in Pucheng, Shaanxi. Chin. J. Rock Mech. Eng. 2013, 32, 1917-1925.

22. Liu, X.J.; Fan, J.Y.; Yu, J.; Gao, X. Solidification of loess using microbial induced carbonate precipitation. J. Mt. Sci. 2021, 18, 265-274. [CrossRef]

23. Moore, C.A.; Donaldson, C.F. Quantifying soil microstructure using fractals. Geotechnique 1995, 11, 105-116. [CrossRef]

24. Cao, Y.; Zhou, J.; Yan, J.J. Research on the microstructure of soft soil under dynamic load considering the influence of cyclic stress ratio and frequency. Rock Soil Mech. 2014, 35, 735-743. 